\section{Clowes and Coleman's Quantitative Chemical Analysis}

An Intermediate Text-Book. Revised and edited by Dr. Julius Grant. Fifteenth edition. Pp. viii+557. (London : J. and A. Churchill, Ltd., 1944.) $21 s$.

ATHOUGH this edition is sixty pages shorter A than the previous one, published in 1938, the new editor states in the preface that much new material has been incorporated and that deletions are confined to doubtful or redundant material, all the classical methods being retained. The whole text has been carefully revised, and the new parts represent standard modern methods which should be described in such a work.

Clowes and Coleman's book, which was first published in 1891, is, so far as the reviewer knows, unique. It is at the same time a student's manual, providing a carefully graded course, and giving all the detail necessary for the successful procedure of the analysis, and also a very useful reference book to practical analysts. It covers a much wider range of subjects than most books of its size, and includes a number of sections on such subjects as water analysis, foods, oils, fats and waxes, soap, organic analyses, gas analysis, and some physico-chemical determinations such as vapour densities and mole. cular weights. The reviewer has often followed the book in past editions in carrying out analyses with which he was not very familiar, and in all cases has found the methods described satisfactory and accurate. The book is full of useful practical laboratory hints, and a good index makes it easy to use. There can be little doubt that in its modernized form, in which important and well-tried new methods find a place, the book will continue to maintain its deserved popularity. The paper, printing and binding are all very good, and the way in which it opens easily will be appreciated by workers at the laboratory bench. The book is recommended to students, teachers and practical analysts.

\section{Cattle at the Crossroads}

Broadcast Discussions in the Home Service of the B.B.C. on Cattle Breeding from the Series 'Farming Today'. Pp. $60+8$ plates. (Worcester : Littlebury and Co., Ltd., n.d.) 5s. net.

SERIES of six broadcast discussions on the breeding, rearing and management of cattle in Great Britain is here printed, almost verbatim, from the original script. Designed principally for the interest and information of the small farmer, each talk is in the form of a dialogue between an expert in the field discussed and an eminent practical farmer, with the chairman (Mr. W. S. Mansfield) guiding the discussions and linking them together.

The speakers were drawn from widely different areas of the country, and the complexity of the cattle industry in Britain is thus well illustrated. Points touched upon-all very briefly-range from mastitis to the effects of the bull licensing scheme, and from hill cattle to artificial insemination. Problems considered are mainly the immediate ones of dairy farm. ing and that of the post-war source of animals for beef production. The viewpoint is that of the producer : there is little consideration of the effect of government policies, and less of marketing arrangements and consumer-preferences.

The title is apt because the average quality of our milking cattle is poor, and greater efficiency will be required after the War. The discussions show how greatly the prospects of improvement depend upon a proper understanding by breeders-the majority of whom are not specialists, but mixed farmers - of their objectives.

\section{Man Studies Life: the Story of Biology}

By G. N. Ridley. (Thinker's Library, No. 97.) Pp. $x+109$. (London: Watts and Co., Ltd., 1944.) $2 s$. $6 d$. net.

AONG specialists it is a common fallacy that, to obtain the interest of the general reader in a new subject, the introduction must consist of a potted version of the whole study under consideration. Usually, after reading one of these potted works, the unfortunate layman has to sit back until he has recovered from the pangs of mental indigestion; and when he surveys this miserable scene, the educationist once more sadly shakes his head and murmurs : "Too much attempted; too little done !" "Man Studies Life" is such a work. The author set out to write a book which badly needed writing - the story of the growth of biological science throughout the ages. In trying to condense that story into a slender volume in which almost every outstanding figure in biology is mentioned, Mr. Ridley has succeeded in producing only a disconnected series of bits and pieces which would be of doubtful value even to the most intelligent layman.

There are few diagrams, one of which is confusing, while another, a time-chart of science, would be extremely valuable if it were more directly related to the text. The whole appearance of the book is too drab to be inviting, a failing which "conformity with the authorized economy standards" does not wholly excuse.

If this book were expanded to four times its present size and presented in a brighter battle-dress, it would be received with avidity by many non-specialist readers.

T. H. H.

\section{Applied Electricity}

By A. W. Hirst. Second edition. Pp. xii +367 . (London, Glasgow and Bombay: Blackie and Son, Ltd., 1944.) $17 s .6 d$. net.

T THE demand for this type of text-book has enabled the author to make some useful additions, particularly chapters on power distribution and thermionics. A chapter on materials gives useful notes on a subject which is too often glossed over, although pivotal in industry. In general, the text is adequate for the new Section B in the A.M.I.E.E. examination, and for the Engineering Cadet course. The treatment is everywhere clear and to the point, except in those aspects to which the reviewer objected in the first edition, namely, the relevant torque in a rotary machine is not on the conductors but on the iron, and the confusion between the terms 'electromotive force' and 'potential difference' (p. 70). While one can properly speak of the 'counter-electro-motiveforce' in an inductance or condenser (better 'capacitor', according to the latest B.S.I. Glossary), because of the storage and delivery of electrical energy temporarily transformed, one simply cannot accept in these days 'counter-electro-motive-force of a resistance'. When the author states a Kirchoff Law as "the algebraic sum of all the E.M.F.s in any closed circuit is zero", what would he say of a uniform closed conducting ring embracing an alternating magnetic field ? There is certainly a single Faraday electromotive force, but there is no potential difference that can be measured anywhere.
L. E. C. H. 